\title{
How Much are Digital Platforms Based on Open Collaboration?
}

\author{
An analysis of technological and knowledge practices and their implications for the platform \\ governance of a sample of 100 cases of collaborative digital platforms in Barcelona
}

\author{
Mayo Fuster Morell \\ Berkman Center for Internet and Society \\ Harvard University \\ Cambridge, USA \\ mayo.fuster@eui.eu
}

\author{
Ricard Espelt \\ Internet Interdisciplinary Institute \\ Open University of Catalonia \\ Barcelona, Spain \\ ricardespelt@uoc.edu
}

\begin{abstract}
From the early cases of FLOSS and Wikipedia, the digital collaborative model of production and consumption has rapidly expanded to other spheres. This article explores to what extent this expansion has maintained the open character of the initial model, specifically the extent to which platform projects follow an open collaborative approach in their technological and knowledge policies and practices, and if this is also reflected in an open approach to governance. The empirical analysis is based on a sample of 100 cases in Barcelona. On the basis of this analysis, we conclude that open modalities of collaborative digital platforms are not prevalent. Around a third of the sample present open modalities of the dimensions analyzed. Different areas (technological, knowledge, or governance) showed different levels of diffusion of open practices. The cases which tended to be open in one dimension also tended to be open in the other dimensions. That is, the analysis points to a correlation between technological, data, and knowledge policies and open and democratic collaborative economy models. These results suggest the importance of open technology and knowledge in adopting an open and democratic collaborative model.
\end{abstract}

\section{CCS CONCEPTS}

- Information systems $\rightarrow$ Crowdsourcing; Collaborative and social computing systems and tools; • Applied computing $\rightarrow$ IT governance; $\bullet$ Software and its engineering $\rightarrow$ Open source model;

\section{ACM Reference Format:}

Mayo Fuster Morell and Ricard Espelt. 2018. How Much are Digital Platforms Based on Open Collaboration?: An analysis of technological and knowledge practices and their implications for the platform governance of a sample of 100 cases of collaborative digital platforms in Barcelona. In Proceedings of 14th International Symposium on Open Collaboration (OpenSym'18), Matt Germonprez (Ed.). ACM, New York, NY, USA, Article 4, 5 pages. https: //doi.org/10.1145/3233391.3233970

Permission to make digital or hard copies of part or all of this work for personal or classroom use is granted without fee provided that copies are not made or distributed for profit or commercial advantage and that copies bear this notice and the full citation on the first page. Copyrights for third-party components of this work must be honored. For all other uses, contact the owner/author(s).

OpenSym'18, August 2918, Paris, France

(c) 2018 Copyright held by the owner/author(s).

ACM ISBN 123-4567-24-567/08/06.

https://doi.org/10.1145/3233391.3233970

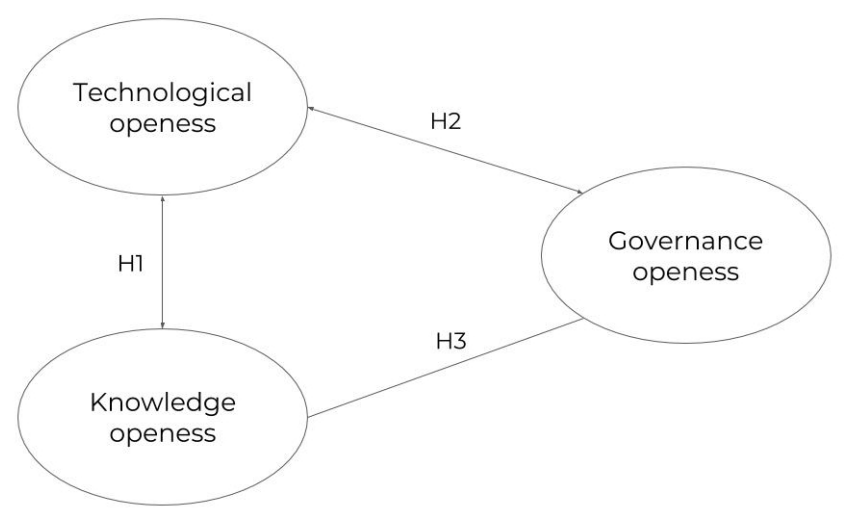

Figure 1: Research model for studying the technological, knowledge, and governance openness of collaborative digital platforms.

\section{INTRODUCTION}

The collaborative consumption and production of capital and labor among distributed groups, supported by a digital platform, is growing rapidly [11]. From the early cases of FLOSS and Wikipedia, described by Benkler in the context of common-based peer production [1], there has been an expansion of the collaborative model to other spheres [11], for instance, to platforms dealing with car sharing, house sharing, and apps exchanging specialized knowledge and notes among university students. However, more recent models based on collaborative production via a platform, such as Airbnb or Uber, have strayed far from the open collaboration logic described in the frame of common-based peer production [3]. This paper addresses the question of how much, since the expansion of the model, open collaboration is present in digital platforms. Openness will be investigated regarding the technological and knowledge policies of digital platforms, and how these relate to openness in the governance model of the platform.

Our departing hypothesis is that three dimensions of openness would tend to reinforce each other (Figure 1). These dimensions are:

H1: Open technological and knowledge practices tend to reinforce each other. That is, more technological openness is connected to knowledge openness in collaborative digital platforms.

$\mathrm{H} 2$ : Technological openness tends to favor more open governance of collaborative digital platforms. 
H3: Knowledge openness tends to favor more open governance of collaborative digital platforms.

The paper presents the following sections: first, we approach the construction of a conceptual framework for collaborative openness regarding technological, knowledge, and governance practices. Next, we explain the methods based on a sample of 100 cases in Barcelona, using data based on web collection and structured interviews. In the results section, we provide descriptive statistics of the openness of technological, knowledge, and governance practices at the platforms, and then test if they are correlated. Finally, we address conclusions and suggest further lines of research.

\section{KEY DIMENSIONS: OPENNESS IN TECHNOLOGY, KNOWLEDGE, AND GOVERNANCE OF PLATFORM}

\subsection{Technological openness}

Technological practices and policies openness refers to the adoption of software and technological architecture that favor freedom and openness.

We have adopted as indicator the type of license of the software code the platform uses. We have categorized the licenses depending on their degree of favorability to openness, or freedom. In this case we have prioritized the robust licenses (copyleft), such as GPL and LGPL, that allow freedom to be maintained throughout the entire chain of users, from its author to the end user, for which they make use of copyleft, forcing derivative work to be maintained with the same copyright regime as the original. Then, in degree of openness, we place the permissive software licenses, such as MIT and BSD, that make the distribution of the work more flexible, either as free or private. Finally, we locate all rights reserved or contents without license.

Regarding technological architecture, two indicators have been adopted. First the type of technological infrastructure on the platform. We categorized these, from more open to less, considering, at the same time, reproducibility (the availability of source code as FOSS) and distribution (which would range from $p 2 p$ to federated to centralized). As: 1) Peer-to-peer (e.g., BitTorrent); 2) Centralized reproducible FLOSS, but not federated (e.g., Media wiki); 3) Federated (e.g., Kune); 4) Centralized in one entrance point (e.g., Wikia); and 5) Centralized but not reproducible because one node is exclusively provided by the platform owner and proprietary (e.g., Facebook). The other indicator considered is the use of blockchain (Yes/No) with the objective to decentralize the platform's technological architecture and open up the community participation.

\subsection{Knowledge openness}

Regarding knowledge platform policies, we have adopted two types of elements: content and data. The content element refers to the type of user-generated content license. The license used and their categorization from more open/free to less were: 1) Public Domain; 2) CC0, 3a) CC BY, 3b) CC BY-SA, 4a) CC BY-NC 4b) CC BY-ND, 5) CC BY-NC-SA, 6) CC BY-NC-ND, 7) All rights reserved or No license. In this case, we have balanced the possibility to share only by author recognition (CC BY) and the possibility to keep the same license attributions (CC BY-SA). In the same sense, we have equated the possibility to create author recognition non-commercial derivatives contents (CC BY-SA) and author recognition with no derivatives (CC BY-ND) but potential commercial contents.

Regarding data policies, the indicator adopted is the ability to access data generated by users, taking into consideration their agreement. The options considered were (from more open to less): 1) API without restrictions; 2) Full data export (data dump); 3) Freely down-loadable as a whole; 4) API with some restrictions; 5) Freely down-loadable in part; and 6) Not possible to export, copy, or access any API.

\subsection{Governance openness}

Regarding platform governance, we have considered several dimensions of governance and the extent to which they adopted an open modality. In that sense, we evaluate governance among value creators at the platform interaction level (matching platform functionalities with the grade that users can participate) and the governance regarding platform provision (considering legal constitution, policies of participation and transparency):

1) The openness of the management of contributors. We have considered: 1.1) the ways users can contribute to the platform content, if it is possible to create new ways of generating content, and whether it is possible to create content or (only) offer/demand/rate products or services; 1.2) the policy of platform participation: whether participation is open without filters, moderated before publication, or moderated after publication; 1.3 ) the possibility of user interaction: if users can communicate among themselves or create groups; and 1.4) if the platform considers different types of user accounts or a single type open to any user.

2) The openness of the election of administrators. We considered: if the users can self-appoint themselves as administrators; if administrators gain privileges automatically through participation; and if administrators are elected from among the general community, by other administrators, or by the infrastructure provided.

3) Decision-making with regard to community interactions, including whether or not there are formal or informal systems for community decision-making, and if the definitions of the formal rules and platform policies are open to user contributions.

4) The type of legal entity and the options for community members to engage with each type of legal entity. We have considered: public administration, university, foundation, association, cooperative, business company, or without legal format.

5) Finally, governance linked to economic management. We considered: 5.1) economic transparency (if the economic balance is accessible to the community or if it is provided publicly); and 5.2) openness in deciding the destination of project benefits (if only project owners or the whole community have channels to be informed of and manage the benefits).

\section{METHODOLOGY}

The methodology is based on the statistical analysis of a sample of 100 cases present in the city of Barcelona [6]. A codebook [5] for data collection (a set of indicators related to the analysis variables) was employed. 
Data collection was based on two methods: web collection and a structured interview. Web collection was based on digital ethnography of the web platforms. It was performed in 100 cases. In addition, we performed a structured interview with 50 of these 100 cases. Finally, during data collection, field notes of general impressions were kept in a field book in order to have detailed qualitative data about study cases.

A single researcher collected the data. To guarantee the reliability of the sample, two other researchers tested the indicators of the codebook with a set of cases, and verified the data collected for some cases by the main data collector. In this way, we controlled the quality of our data.

To develop the analysis, we generated descriptive statistics of defined variables and correlation analysis in order to study the relation between open technology, knowledge openness variables, and open governance.

For the statistical analysis of the data, we applied different nonparametric tests. We were aware that non-parametric methods are not as powerful as parametric ones. However, because nonparametric methods make fewer assumptions, they are more flexible, robust, and applicable to non-quantitative (categorical/nominal) variables. Some of the tests that we applied to our dataset were bivariate non-parametric correlations calculated using Spearman's correlation [13].

To create the sample, the use of a probability or random sample has several advantages. The most important benefit is the ability to make inferences about the population with a certain degree of confidence. Randomization increases the likelihood that a large sample will reflect the characteristics of the underlying population by avoiding assignment or selection based on the value of the variables of interest. However, randomization does not guarantee a representative sample per se. In addition, random selection involves the risk of missing relevant cases. Finally, there are limitations (such as uncertainty regarding representativeness) to applying randomness to a highly diverse population with unknown size and boundaries. In other words, using probability samples requires knowledge of the population. For instance, a list or census of the population, or at least a partial list (at some level) of the population. This is not the case for collaborative digital platforms, which are diverse and whose universe is unknown.

Given the lack of adequate conditions and the unsuitability of developing a probability sample of diverse collaborative digital platform experiences, as well as the absence of a comparability goal, we used non-proportional quota sampling to build the sample of 100 cases out of the initial more than 1,000 current cases of commons-based peer production identified in the city of Barcelona by the P2Pvalue directory project [4]. We ensured the inclusion of a mix of platform experiences to reflect the heterogeneity of the collaborative digital platforms, taking into account projects promoted by different type of actors (public administration, companies, cooperatives, communities without legal format), areas (cultural, tourism, mobility, etc.), goals (knowledge co-creation, community engagement, business) and profit and non-profit oriented. From the initial list of more than 1,000 cases identified, we used different matching criteria to ensure the diversity of the sample. Thus, the selection takes into account local cases and platforms with global activity, including Barcelona. This approach matches with a vast

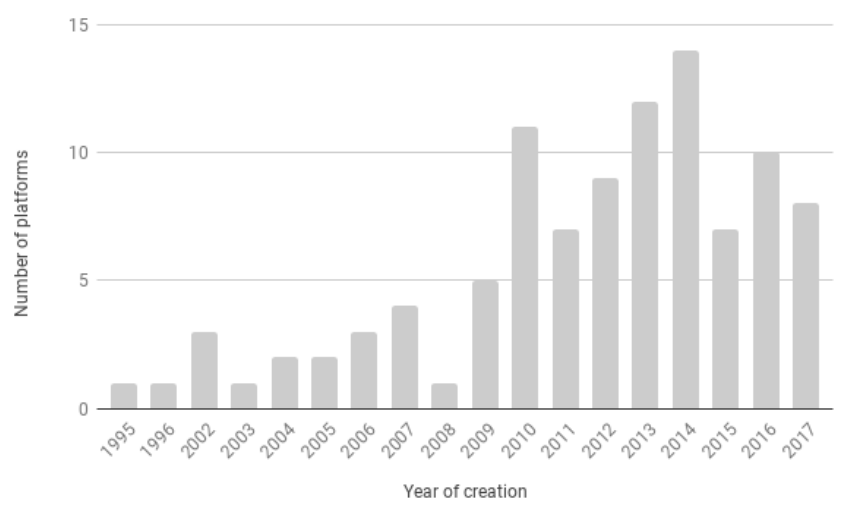

Figure 2: Year of creation.

number of cities, where local and global platforms develop their activity in the city spectrum [7].

Additionally, in order to improve the robustness of our sample, we ensured the systematization of the sampling. We selected the most relevant 100 cases on the basis of: 1) Projects with activity in Barcelona; 2) Projects based on or supported by a digital platform; 3) Projects based on collaborative production; and 4) Projects with a significant level of activity of participation (platforms which have at least reached the level of having registered and active accounts by users, so in some stage of of community engagement).

Even if the universe is variable, we consider that we reached a large part of the experience in Barcelona with an initial mapping of more than 1,000 cases, since the P2PValue directory is periodically reviewed and the selection collect the filters referred before. $64,36 \%$ of the cases have the principal headquarters in the city of Barcelona, 11,88 in the region (Catalonia), 16,83\% in the rest of the country (Spain), 4,95\% in Europe and 1,96\% in the rest of the world.

Regarding the year of creation (Figure 2), 77,23\% of the cases have been created from 2010 . In respect of the stage of evolution, $9,90 \%$ of platforms have an early stage of implementation of the idea or business model, 10,89\% have a stable and full operational mode, $22,77 \%$ are in a growing phase, $52,48 \%$ can be considered mature because are a main reference in their field and $3,96 \%$ are without current operation.

\section{RESULTS: OPEN COLLABORATION AT PLATFORMS}

\subsection{Technological openness}

Focusing on software openness, $33,66 \%$ of the platforms were based on copyrighted software while $19,80 \%$ used software without any type of license. At the other end of the scale, 2,97\% of them took advantage of software with a public domain license, while 36.63 adopted one of the different grades of free licenses.

With regard to technological infrastructure and architecture openness, $35,64 \%$ of platforms were open to reproducibility. Of these, $10,89 \%$ had a peer-to-peer architecture, $18.8 \%$ used centralized reproducible FLOSS, and 5,94\% used centralized FLOSS. $44.55 \%$ of 
the collaborative digital platforms studied were not open to being reproduced.

Additionally, $38 \%$ of projects use or plant to use blockchain as a way to decentralize power and control of the platform technology, while $44 \%$ were not interested and 18 did not answer the question. In sum, $39.6 \%$ of the projects were based on a free license software, $35.64 \%$ were based on an open architecture, and 38 of projects had interest in exploring other forms of decentralized technologies. The openness of technological practices in the three modalities investigated was not used by the majority of cases. However, it constituted more than a third of the cases.

Finally, the technological openness correlation analysis shows a relationship between the platform's software and the type of infrastructure architecture. While with less significance, there is also a correlation between the openness of the platform code and the use of blockchain technology. In other words, different types of openness in technological practices tend to reinforce each other.

\subsection{Knowledge openness}

When it comes to user-generated content, the majority of collaborative digital platforms analyzed had a private copyright license (36.63\%) or dismissed any type of license $(23.76 \%)$, while $2.97 \%$ had a public domain license and $32.67 \%$ had a Creative Commons license. While only $20.79 \%$ of the platforms studied had an option to export part or all of the data generated by their users.

An internal correlation analysis of knowledge policies highlights a relationship between user-generated content licenses and how the data is exported or how copying of the complete resource is technically facilitated.

\subsection{Governance openness}

Regarding the management of contributors, there was almost a balance between platforms where users create new ways of adding or generating content with others $(39.6 \%)$ and the ones which focused on offering, demanding, or rating products or services (42.6\%). At the same time, the majority of collaborative digital platforms did not constrain user participation.

In $35.6 \%$ of the platforms, members published without filters, and in only $25.7 \%$ was content moderated prior to publishing. $57.4 \%$ of platforms allowed participants to be part of groups or communicate among themselves. In spite of that, the majority of projects analyzed $(60 \%)$ had different types of user accounts, and the administrators were chosen by the founders or platform providers.

Regarding the decision-making process for community interactions, $56 \%$ of platforms have formally or informally defined systems to involve the community in the decision-making process. On $54 \%$ of the projects, users can participate in the definition of formal rules and policies.

Regarding the legal entity, $44.6 \%$ of the platforms studied belonged legally to a business structure (I.e. SL, SA, SCP etc.), while 4\% came from the Public Administration, 2 from the university, $17.8 \%$ from non-profit associations, $5 \%$ from foundations, and $12.9 \%$ from cooperatives, while $13.9 \%$ did not have a defined legal format.

Regarding the connection between platform governance and economic management, in $76 \%$ of cases the economic balance was accessible by members of the project's legal entity and in $38 \%$ this information was publicly available. In half of the instances (50\%), the owners of the platform decided the destination of the economic benefits.

Governance openness correlations highlight some strong connections between the variables studied. First, a connection appears between the openness to users contributing to the digital platform and the type of legal entity. Second, a connection appears between the way a user can participate in the definition of the rules and policies, how the platform administrators are chosen, and who controls decision regarding economic benefits. Finally, another connection appears between the type of legal entity behind the platform and its economic management, in terms of who decides the destination of economic benefits and the transparency of economic balance.

Relation between technological, knowledge, and governance openness The analysis points to a correlation between the three dimensions considered in this investigation: technological, knowledge, and governance openness.

The results confirm our general hypothesis that openness principles are reinforced by the different dimensions in which it is applied. The results also confirm the three specific hypotheses. The most relevant correlation from the analysis is that between the dimensions of knowledge and technological openness $\left(0.46^{* *}\right)$. This suggests that the adoption of open technology and open knowledge policies by a collaborative digital platform are related. The double correlation, with similar values, of technological openness with open governance $\left(0.36^{* *}\right)$ and knowledge openness with governance openness $\left(0.38^{* *}\right)$, suggest the importance of knowledge and technological policy openness in favoring open governance.

\section{DISCUSSION AND CONCLUSION}

The conclusions we draw from our investigation have two premises that must be located in advance. On the one hand, we have done a case study of the city of Barcelona, so the conclusions are partly extrapolated to other cities where global collaborative or similar business platforms appear. On the other hand, the generation of criteria to define and categorize the technological, knowledge and governance openness of collaborative economy platforms has its own controversies and limitations.

In any case, based on our analysis of a sample of 100 cases of collaborative digital platforms in Barcelona, we could conclude that open modes of collaborative digital platforms are not prevalent. The diffusion of open practices varies depending on the area analyzed: technological, knowledge, or governance openness.

The area with the greatest presence of openness is that of knowledge practices in concrete user-generated content, as open practices are present in $35.64 \%$ of the sample. In knowledge practices relating to data openness, however, it goes down to $20.79 \%$ of the sample. Openness of technological practices in the three modalities investigated was not practiced by the majority, but open options constituted more than a third of the cases $39.6 \%$ of the projects are based on a free software license, $35.64 \%$ are based on open architecture, and 38 of the projects have interest in exploring other forms of decentralized technology).

Two factors may explain this result. The first is the desire to restrict use of the website's software to the platform owners. The second is the low level of attention to software, content license, 
and open data exportation in the growing platform cooperativism model (cooperatively owned, democratically governed businesses that establish a digital platform to facilitate the sale of goods and services).

Regarding governance, the most prevalent points of openness are seen in the policies of publication without filters or moderated only before publishing $(61.3 \%)$, the ability to create groups or communicate with other users (57.4\%), and internal transparency (76\%). The least-used openness policies regard the administrators' election (only $38 \%$ of platforms had a democratic or meritocratic process to elect administrators) and who decides the destination of the economic platform's benefits (only 40 were decided by whole community). Therefore, when we look into the core of governance (platform or economic administration) the grade of openness is lower than when we study openness about member participation. Still, overall open governance of the platforms was adopted by $38 \%$ to $61.3 \%$ (depending on the specific governance indicator), which constituted a higher diffusion of openness in terms of platform governance, compared to technological or knowledge practices.

We could conclude on the basis of the data that openness collaboration in platforms is not irrelevant, but it is not prevalent neither, as seen in around one third of the sample. Furthermore, the cases which tended to be open in one dimension also tended to be open in the other dimensions. This suggests that a segment of the overall platform ecosystem could be characterized as more open, while a larger segment is not based on any of the methods of openness considered.

We have shown a connection between the indicators that define knowledge and technology policies, which, at the same time, are intertwined with governance. In that sense, our investigation suggests that openness in technology and data areas tends to also be reflected in other areas like governance. In spite of the relevance of the sample, however, the limited number of cases requires caution in analyzing its results and conclusions.

Regarding platform governance, we observe the active role of members in some key aspects of the democracy of the platform: defining the rules, involvement in the decision-making process, and internal transparency of the economic balance. We observed better open behavior in the realm of open governance than in the realms of technological, knowledge, and data openness. However, the correlation analysis shows that openness in participation, knowledge and technology are also connected to the governance of the project. To sum up, the results of this investigation suggest a better proliferation of governance openness models than open technological, knowledge, and data ones. The results also suggest the interrelated strength of these three dimensions in the promotion of the open collaborative ecosystem.

Regarding the city of Barcelona, in the current context of the expansion of the social solidarity economy movement [9], and taking into account the social and economic sustainability qualities of Social and Solidarity Economic organizations, with open governance models based on a tradition of cooperativism [2],[14], we can expect new strengths in the growth of cooperatives and more sustainable alternatives for expansion in collaborative digital platforms [8]. The digital domain opens up new possibilities for the cooperative tradition [12], adopting platform forms such as opencoops [16] or platform coops [15] based on technological, knowledge, and data openness [10]. This leads us to suggest that an expansion of the more open models of platforms could accelerate in coming years, connected to the growth of cooperativism in the digital sector. This is a question requiring further investigation.

\section{ACKNOWLEDGMENTS}

This research is part of the work carried out by the Dimmons research group in the framework of the DECODE project (funded by the European Union's Horizon 2020 Programme, under grant agreement number 732546). We would like to thank E. Senabre, E. Rosello, M. Rocas, G. Smorto, B. Carballa, P. Imperatore, M. Rebordosa, and N. Andrea for their contribution to the data collection, and C. Malpica for her help in data analysis.

\section{REFERENCES}

[1] Yochai Benkler. 2006. The wealth of networks: How social production transforms markets and freedom. Yale University Press, London, UK.

[2] Johnston Birchall and Lou Hammond Ketilson. 2009. Resilience of the cooperative business model in times of crisis. International Labour Organisation, Geneva, Switzerland.

[3] Cristiano Codagnone, Federico Biagi, and Fabienne Abadie. 2016. The passions and the interests: Unpacking the'sharing economy'. (2016).

[4] Dimmons. 2016. P2Pvalue Catalan Directory. Retrieved May 14, 2018 from http://directori.p2pvalue.eu

[5] Dimmons. 2018. Codebook used for data collection. Retrieved May 5, 2018 from http://dimmons.net/wp-content/uploads/2018/05/codebook opensym2018-ColÂůlacy-codebook.pdf

[6] Dimmons. 2018. Research cases list. Retrieved May 14, 2018 from http://dimmons. net/wp-content/uploads/2018/05/cases_list.pdf

[7] World Economic Forum. 2017. Collaboration in Cities: From Sharing to âĂŸSharing Economyâ̆ÁŹ. Technical Report. White Paper.

[8] Mayo Fuster and Ricard Espelt. 2017. Platform Cooperativism Holistic Characterization and Delimitation: 10 Cases of Barcelona Ecosystem. In Re-embedding the Social: Cooperatives, Political Consumerism and Alternative Lifestyles. SASE.

[9] Ivan Miró i Acedo and Anna Fernàndez Montes. 2016. Social and Solidarity Economy in Barcelona. Marge Books, Barcelona, Spain.

[10] Mayo Fuster Morell. 2017. Towards a theory of value of platform cooperativism. OR Books. (inbook).

[11] Mayo Fuster Morell, Jorge L Salcedo, and Marco Berlinguer. 2016. Debate about the concept of value in Commons-Based Peer Production. In International Conference on Internet Science. Springer, 27-41.

[12] Robin Murray. 2010. Co-operation in the Age of Google. Skinner (2012) Open Co-operation: Towards a Blueprint for a Co-operative Decade. R. Murray (2010) Co-operation in the Age of Google (http://www.uk.coop/ageofgoogle) (2010).

[13] Han Woo Park and Mike Thelwall. 2005. The network approach to web hyperlink research and its utility for science communication. Virtual methods: issues in social research on the Internet (2005), 171-182.

[14] Bruno Roelants, Diana Dovgan, Hyungsik Eum, and Elisa Terrasi. 2012. The resilience of the cooperative model. How worker cooperatives, social cooperatives and other (2012)

[15] Trebor Scholz. 2016. Platform cooperativism. Challenging the corporate sharing economy. Rosa Luxemburg Stiftung, New York.

[16] Boris Veytsman. [n. d.]. Cooperativismo abierto para la era del P2P. Retrieved April 1, 2017 from http://www.guerrillatranslation.es/2014/07/03/ cooperativismo-abierto-para-la-era-p2p 